\title{
Microbial Spectrum and Resistance Patterns in Ocular Infections: A 15-Year Review in East China
}

\author{
Chunhong Liu ${ }^{1,2, *}$ \\ Baixing Ding ${ }^{3, *}$ \\ Jian Ji $\mathrm{i}^{\prime}$ \\ Zhujian Wang' \\ Huiwen Chen' \\ Wenjun $\mathrm{CaO}{ }^{1,2}$ \\ 'Clinical Laboratory, Eye \& ENT Hospital, \\ Fudan University, Shanghai, People's \\ Republic of China; ${ }^{2}$ Eye Institute and \\ Department of Ophthalmology, Eye \& \\ ENT Hospital, Fudan University, Shanghai, \\ People's Republic of China; ${ }^{3}$ Institute of \\ Antibiotics, Huashan Hospital, Fudan \\ University, Shanghai, People's Republic of \\ China
}

*These authors contributed equally to this work
Correspondence: Wenjun Cao Emailwgkjyk@aliyun.com
Purpose: To report antibiotic resistance rates and trends of common ocular isolates collected over a 15-year period.

Methods: We collected 3533 isolates from July 1, 2005 to July 31, 2020. Antibiotic sensitivity was determined according to the guidelines of the Clinical and Laboratory Standards Institute. Chi-squared $\left(\chi^{2}\right)$ test was used to analyze changes in antibiotic susceptibility over 15 years.

Results: Among the 3533 isolates, the predominant pathogens were the staphylococcal species. Methicillin resistance was observed in 381 Staphylococcus aureus ( $S$. aureus) isolates (46.4\%) and 1888 coagulase-negative staphylococci (CoNS) isolates $(61.1 \%)$, and methicillin-resistant (MR) isolates had a high probability of concurrent resistance to fluoroquinolones and aminoglycosides. The mean percentage of resistance in staphylococcal isolates did not reach statistical significance across patient age groups $(P=0.87)$. Methicillin resistance did not increase in the CoNS $(P=0.546)$ isolates, and resistance to methicillin slightly decreased among $S$. aureus $(P=0.04)$ isolates over 15 years. Additional exploratory analysis revealed a small decrease in resistance to tobramycin $(P=0.01)$ and chloramphenicol $(P<0.001)$ among the CoNS isolates. All staphylococcal isolates were susceptible to vancomycin.

Conclusion: Staphylococci were the most common microorganisms responsible for causing ocular infections. Antibiotic resistance was high among staphylococci, with nearly half of these isolates were resistant to methicillin and these had a high probability of concurrent resistance among MR staphylococci to other antibiotics. Overall, ocular resistance did not significantly change during the 15 -year study period. We conclude that continued surveillance of antibiotic resistance provides critical data to guide antibiotic selection.

Keywords: methicillin, antibiotic resistance, ocular isolate, staphylococci

\section{Introduction}

The emergence of antibiotic resistance among bacterial pathogens poses a serious therapeutic challenge to public health. ${ }^{1-6}$ In ophthalmology, antibiotic resistance among pathogens has become a growing concern in the last decades, ${ }^{7-13}$ partially because of an increase in the number of contact-lens users and immunecompromised patients. ${ }^{14-18}$ According to the Antibiotic Resistance Monitoring in Ocular Microorganisms in the USA (ARMOR), methicillin resistance is prevalent among staphylococcal isolates from ocular infections, with many strains demonstrating multidrug resistance. ${ }^{19}$ The emergence of antibiotic resistance among bacterial pathogens can complicate the choice of antibiotic treatment and threaten vision. 
Ocular infections are serious clinical conditions that can lead to vision loss. ${ }^{20,21}$ Timely and appropriate treatment is essential to prevent this loss from being irreversible. $^{22}$ In the absence of faster treatment approaches with higher accuracy, ophthalmologists continue to treat ocular infections empirically. However, the current recommendation for empirical therapy requires further validation studies. Surveillance of ocular isolates and antibiotic resistance provides valuable information to aid the choice of empirical treatment.

In this study, we aimed to provide data for determining the optimal use of antibiotics and tools for target-oriented infection control measures. Using isolates collected during July 2005-July 2020, we retrospectively analyzed the trends of microbial-spectrum and antibiotic-resistance profiles at a tertiary hospital in Shanghai, China. As no largescale, retrospective studies have been performed in this region, our results would benefit efforts to identify the most effective treatment regimen.

\section{Methods}

We reported antibiotic resistance among ocular isolates collected from July 1, 2005 to July 31, 2020 at the Eye \& ENT Hospital. The study was performed in compliance with the Declaration of Helsinki and was approved by the hospital's ethics committee (No. 2015011). Informed consent from patients was not required as the data were obtained from patient clinical records in the medical database. We confirm that the patient data complied with relevant data protection and privacy regulations.

The ocular sites from which bacteria were isolated were the conjunctiva, cornea, aqueous humor, vitreous humor, and intraocular foreign bodies. Staphylococci were grouped as methicillin-resistant (MR) or methicillin-susceptible (MS). Minimum inhibitory concentrations were interpreted as susceptible, intermediate, or resistant according to the Clinical and Laboratory Standards Institute. ${ }^{23} \mathrm{~A}$ one-way analysis of variance (ANOVA) was used to evaluate antibiotic resistance rates by the age of the patients. The changes in the resistance rates over time were determined using the $\chi^{2}$ test for trends.

Statistical analyses were performed using SPSS version 21.0 for Windows (SPSS Inc., Chicago, IL, USA) or Prism version 5.01 (GraphPad Software). Significance was set at $P<0.05$.

\section{Results}

\section{Source of Isolates}

We collected 3533 isolates from the same number of patients, with 2512 (71.1\%) males and 935 (26.5\%) females; sex was not reported for 86 patients $(2.4 \%)$. We had data of the originating patient ages of 3447 isolates (345 isolates, $<10$ years; 170 isolates, 10-19 years; 532 isolates, 20-29 years; 590 isolates, 30-39 years; 645 isolates, $40-49$ years; 528 isolates, 50-59 years; 372 isolates, $60-69$ years; 265 isolates, $\geq 70$ years).

Additionally, we had details of the anatomical sources for 3533 isolates, and they were conjunctiva $(\mathrm{n}=1286)$, cornea $(\mathrm{n}=388)$, aqueous humor $(\mathrm{n}=$ $210)$, vitreous humor $(\mathrm{n}=715)$, and intraocular foreign body $(\mathrm{n}=934)$. Table 1 shows a detailed overview of isolates.

\section{Microbial Spectrum}

Most isolates $(82.5 \%, 2916)$ were gram-positive, and the remaining $(17.5 \%, 617)$ were gram-negative. Overall, the predominant pathogens were staphylococcal species (coagulase-negative staphylococci [CoNS] in 1888 cases and Staphylococcus aureus [S. aureus] in 381). Pseudomonas aeruginosa was the most frequently isolated gramnegative bacterium (Table 2).

Table I Demographics and Clinical Characteristics

\begin{tabular}{|l|l|l|}
\hline Variable & & N (\%) \\
\hline Age & $<10$ & $345(9.8 \%)$ \\
& $10-19$ & $170(4.8 \%)$ \\
& $20-29$ & $532(15.1 \%)$ \\
& $30-39$ & $590(16.7 \%)$ \\
& $40-49$ & $645(18.3 \%)$ \\
& $50-59$ & $528(14.9 \%)$ \\
& $60-69$ & $372(10.5 \%)$ \\
& $>70$ & $265(7.5 \%)$ \\
& Unknown & $86(2.4 \%)$ \\
\hline \multirow{2}{*}{ Gender } & Male & $2512(71.1 \%)$ \\
& Female & $935(26.5 \%)$ \\
& Unknown & $86(2.4 \%)$ \\
\hline \multirow{2}{*}{ Culture Location } & Conjunctiva & $1286(36.4 \%)$ \\
& Intraocular foreign body & $934(26.4 \%)$ \\
& Vitreous humor & $715(20.2 \%)$ \\
& Cornea & $388(11.0 \%)$ \\
& Aqueous humor & $210(5.9 \%)$ \\
\hline
\end{tabular}

Notes: \%, percent of total; $n$, total number of isolates. 
Table 2 Microbiological Spectrum of the Ocular Samples

\begin{tabular}{|l|c|c|}
\hline Isolates & N & $\%$ Total \\
\hline Gram positive & 2916 & $82.5 \%$ \\
Coagulase-negative staphylococci & 1888 & $53.4 \%$ \\
Staphylococcus aureus & 381 & $10.8 \%$ \\
Streptococcus species & 236 & $6.7 \%$ \\
Bacillus species & 229 & $6.5 \%$ \\
Corynebacterium species & 92 & $2.6 \%$ \\
Streptococcus pneumonia & 60 & $1.7 \%$ \\
Other Gram-positive bacteria & 30 & $0.8 \%$ \\
\hline Gram negative & 617 & $17.5 \%$ \\
Enterobacteriaceae & 235 & $6.7 \%$ \\
Pseudomonas aeruginosa & 126 & $3.6 \%$ \\
Other non-fermentative bacilli & 205 & $5.8 \%$ \\
Neisseria & 34 & $1.0 \%$ \\
Other Gram-negative bacteria & 17 & $0.5 \%$ \\
\hline Total & 3533 & $100 \%$ \\
\hline
\end{tabular}

Notes: \%, percent of total; N, number of isolates.

\section{Antibiotic Resistance Rates}

All staphylococcal species were susceptible to vancomycin $(100 \%) \quad$ (Table 3). Of the methicillin-resistant Staphylococcus aureus (MRSA) isolates, 48.0\%, 46.4\%, $41.0 \%$, and $57.6 \%$ were resistant to ciprofloxacin, ofloxacin, tobramycin, and TMP-SMX, respectively. Resistance to chloramphenicol was $22.6 \%$ and that to moxifloxacin was $25.0 \%$. Only $6.5 \%$ of methicillin-susceptible Staphylococcus aureus (MSSA) was resistant to moxifloxacin. MRSA isolates had higher resistance rates to ciprofloxacin $(P<$ $0.0001)$, ofloxacin $(P<0.0001)$, levofloxacin $(P=0.002)$, and TMP-SMX $(P<0.0001)$ than MSSA isolates (Table 3$)$. The resistance rates to other drugs were not significant. Of the 1888 methicillin-resistant CoNS (MRCoNS) isolates, $48.7 \%, 42.4 \%$, and $48.8 \%$ were resistant to ciprofloxacin, ofloxacin, and TMP-SMX, respectively. Similar to MRSA isolates, MRCoNS isolates had higher resistance rates to these drugs than MSSA isolates $(P<0.005$; Figure 1).

\section{Antibiotic Resistance Rates by Patient Age}

The mean percentage of resistance in staphylococcal isolates did not reach statistical significance across patient age groups $(P=0.87$; Figure 2$)$.

\section{Antibiotic Resistance Trends Over Time}

We found a few changes in the resistance rates of the isolated over 15 years (Figure 3). Methicillin resistance
Table 3 Antibiotic Resistance Profiles for Isolates

\begin{tabular}{|c|c|c|c|c|}
\hline Antibiotic & & $\%(n)$ & $x^{2}$ & $P$ \\
\hline \multirow[t]{4}{*}{ Ciprofloxacin } & MSCoNS & $20.8(70 I)$ & 140.4 & $\leq \underline{0.0001}$ \\
\hline & MRCoNS & $48.7(1125)$ & & \\
\hline & MSSA & $22.0(200)$ & 31 & $\leq \underline{0.0001}$ \\
\hline & MRSA & $48.0(174)$ & & \\
\hline \multirow[t]{4}{*}{ Ofloxacin } & MSCoNS & $22.0(480)$ & 43.9 & $\leq 0.0001$ \\
\hline & MRCoNS & $42.4(603)$ & & \\
\hline & MSSA & $15.5(142)$ & 29.3 & $\leq 0.0001$ \\
\hline & MRSA & $46.4(139)$ & & \\
\hline \multirow[t]{4}{*}{ Levofloxacin } & MSCoNS & $10.5(4 \mid 8)$ & 107.6 & $\leq \underline{0.0001}$ \\
\hline & MRCoNS & $39.2(769)$ & & \\
\hline & MSSA & I5.3(144) & 9.2 & $\underline{0.002}$ \\
\hline & MRSA & $31.4(105)$ & & \\
\hline \multirow[t]{4}{*}{ Chloramphenicol } & MSCoNS & 19.6(577) & 30.9 & $\leq 0.000 \mathrm{I}$ \\
\hline & MRCoNS & $32.9(875)$ & & \\
\hline & MSSA & $14.7(163)$ & 3.2 & 0.072 \\
\hline & MRSA & $22.6(155)$ & & \\
\hline \multirow[t]{4}{*}{ Tobramycin } & MSCoNS & $24.8(436)$ & 31.1 & $\leq 0.0001$ \\
\hline & MRCoNS & $38.9(545)$ & & \\
\hline & MSSA & $26.3(114)$ & 0.9 & 0.351 \\
\hline & MRSA & $41.0(122)$ & & \\
\hline \multirow[t]{4}{*}{ TMP-SMX } & MSCoNS & $40.3(528)$ & 8.7 & $\underline{0.003}$ \\
\hline & MRCoNS & $48.8(858)$ & & \\
\hline & MSSA & $32.3(129)$ & 15.6 & $\leq 0.000 \mathrm{I}$ \\
\hline & MRSA & $57.6(118)$ & & \\
\hline \multirow[t]{4}{*}{ Moxifloxacin } & MSCoNS & $2.3(132)$ & 17.7 & $\leq \underline{0.0001}$ \\
\hline & MRCoNS & $16.9(236)$ & & \\
\hline & MSSA & $6.5(31)$ & 3.5 & 0.06 \\
\hline & MRSA & $25.0(20)$ & & \\
\hline \multirow[t]{4}{*}{ Vancomycin } & MSCoNS & $0(701)$ & I & I \\
\hline & MRCoNS & $0(\mid I 25)$ & & \\
\hline & MSSA & $0(200)$ & 1 & 1 \\
\hline & MRSA & $0(174)$ & & \\
\hline
\end{tabular}

Notes: \%, percent resistance; $\mathrm{n}$, total number of isolates tested; Underlined values mean statistically significant at $P<0.05$.

Abbreviations: MRCoNS, methicillin-resistant coagulase-negative staphylococci; MSCoNS, methicillin-susceptible coagulase-negative staphylococci; MRSA, methicillin-resistant Staphylococcus aureus; MSSA, methicillin-susceptible Staphylococcus aureus.

of the CoNS isolates did not increase $(P=0.546)$, rather it slightly decreased among $S$. aureus isolates $(P=0.04)$. Additional exploratory analysis revealed a small decrease in resistance to tobramycin $(P=0.01)$ and chloramphenicol $(P<0.001)$ among the CoNS isolates (Table 4). There were no other changes in the resistance rates. 
A
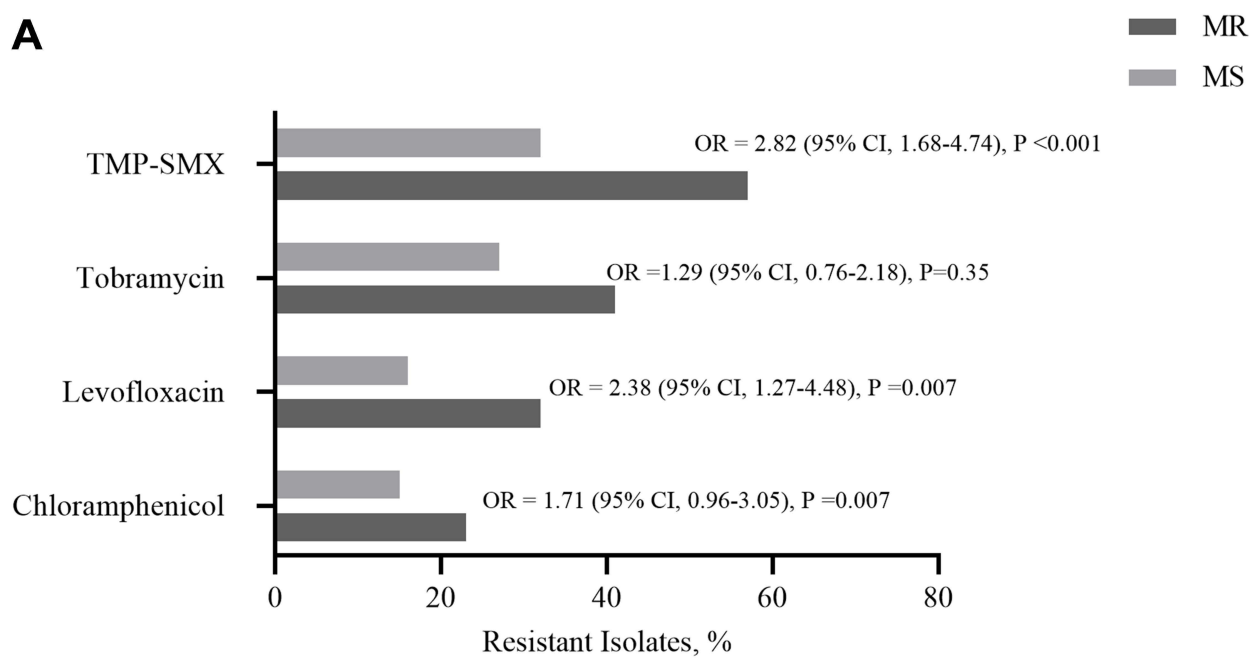

B

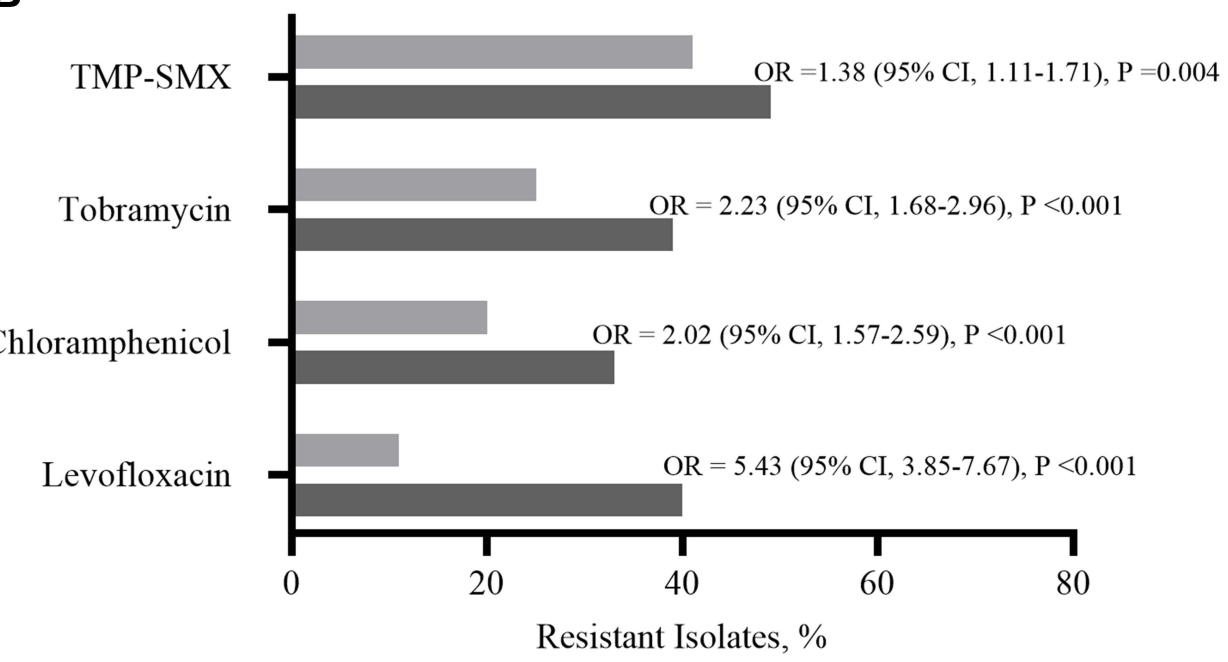

Figure I Resistance to other antibiotic classes among isolates by methicillin resistance status. (A) Staphylococcus aureus. (B) Coagulase-negative staphylococci. Abbreviations: MR, methicillin resistant; MS, methicillin susceptible.

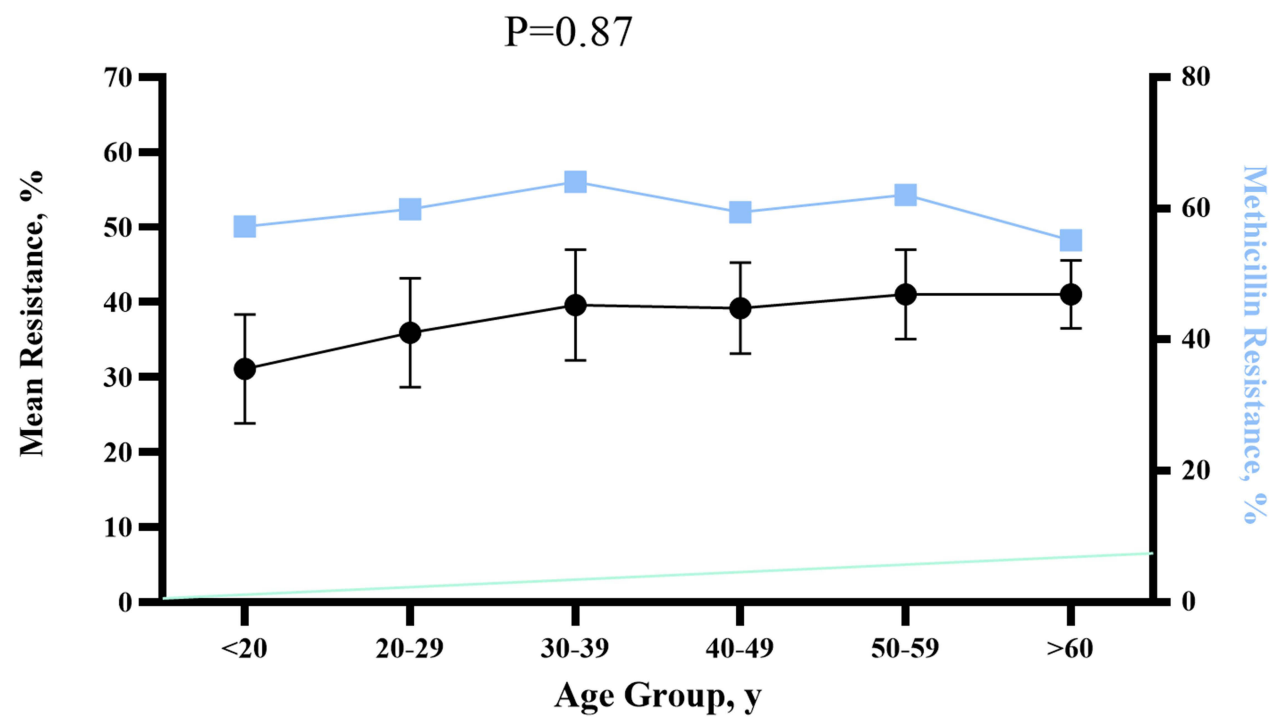

Figure 2 Resistance among ocular isolates by patient age. Data are expressed as mean (SE) percentage of resistance (black line) and percentage of methicillin resistance (blue line) by decade of life. $P$ values are calculated using analysis of variance of the mean percentage of resistance. 

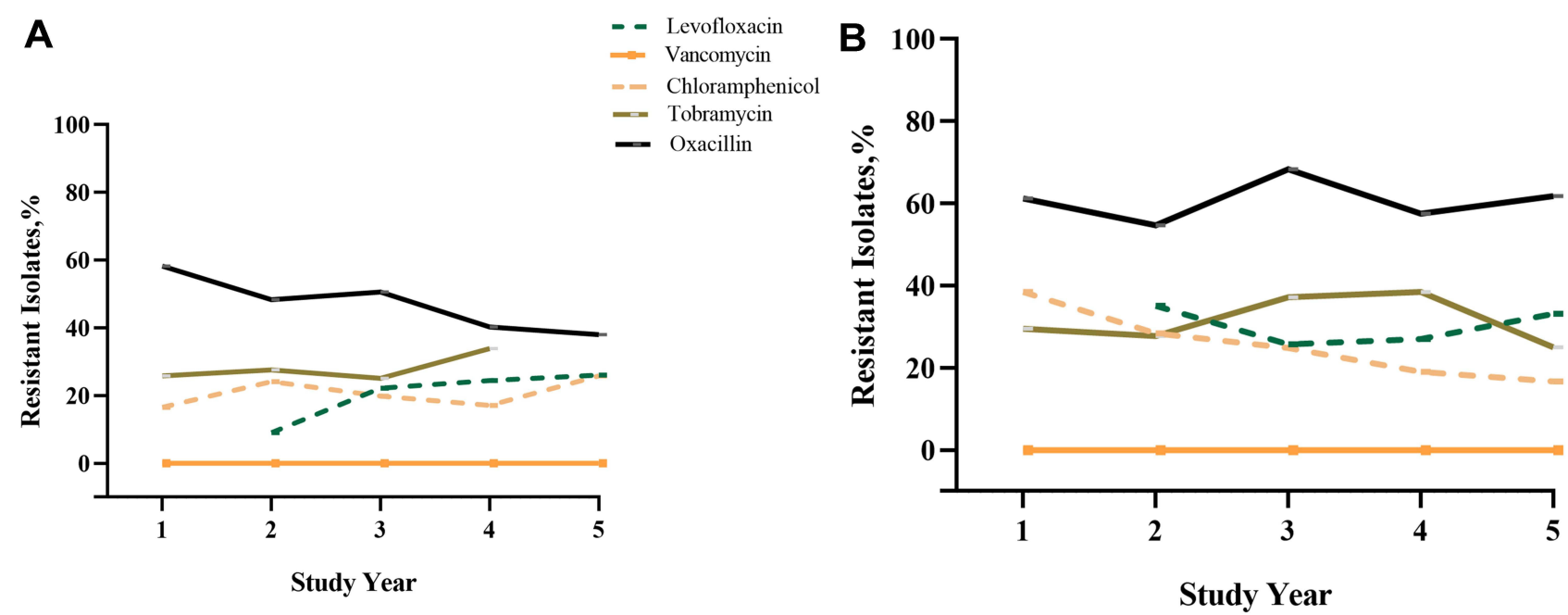

Figure 3 Antibiotic resistance trends over time. (A) Staphylococcus aureus. (B) Coagulase-negative staphylococci.

\section{Discussion}

Ocular infection is a devastating complication that can have serious anatomical and functional consequences. ${ }^{24-26}$ Because the treatment options for ocular infections are limited, antibiotics are commonly used, and increasing resistance to antibiotics is a serious problem that must be overcome. In this study, we investigated the major causative bacteria of ocular infections and antibiotic resistance among ocular pathogens, especially among $S$. aureus and CoNS isolates, to aid the selection of appropriate antibiotics.

Regarding keratitis and conjunctivitis isolates, the most common causative organism of suspected conjunctivitis was staphylococci, similar to that reported previously. ${ }^{27,28}$ We also found CoNS to be the most common isolate in conjunctivitis, followed by $S$. aureus. The latter finding differs from that of a previous study. ${ }^{26}$ Thus, the high CoNS prevalence we observed may be unique to our public healthcare setting or represent a change in local ocular pathogens. Gram-positive bacteria, and specifically staphylococcal species, remained the predominant

Table 4 Antibiotic Susceptibility Trends for Staphylococci from 2005 to 2020

\begin{tabular}{|l|l|l|}
\hline P value* & S. aureus & CoNS \\
\hline Levofloxacin & 0.408 & 0.26 \\
Chloramphenicol & 0.553 & $\underline{\underline{\underline{0} .001}}$ \\
Tobramycin & 0.317 & $\underline{0.01}$ \\
Methicillin & $\underline{0.04}$ & 0.546 \\
\hline
\end{tabular}

Notes: $* \chi^{2}$ test for trend. Underlined values mean statistically significant at $P<0.05$. Abbreviations: S. aureus, Staphylococcus aureus; CoNS, coagulase-negative staphylococci. pathogens in patients with endophthalmitis. These patients also had a relatively high incidence of $B$ cereus, a highly virulent bacterium that causes rapid progression to panophthalmitis. ${ }^{29,30}$

The results show that antibiotic resistance continues to be high among staphylococcal species, with nearly half of the isolates resistant to methicillin and a high probability of concurrent resistance among MR staphylococci to other commonly used antibiotics. ${ }^{31}$ These findings are consistent with data from other studies. ${ }^{19,32,33}$ The MR isolates were 1-3 times more likely to exhibit ciprofloxacin, chloramphenicol, TMP-SMX, levofloxacin, or tobramycin resistance than MS strains, and most MR staphylococci isolates were multidrug-resistant. Within this group, MRSA and MRCoNS isolates were 4 and 7 times more likely to be moxifloxacinresistant, respectively, although they were sensitive to vancomycin. The cumulative rates of methicillin resistance among $S$. aureus and CoNS isolates in our study $(46.5 \%$ and $61.1 \%$, respectively) were slightly higher than corresponding rates from the ARMOR study for isolates collected during 2009-2015 (42.2\% and 49.7\%, respectively). ${ }^{19}$ Antibiotic resistance patterns vary over time, geographic location, ethnic groups, and climatic factors. ${ }^{34-39}$ In this study, $S$. aureus exhibited a decrease in resistance to oxacillin $(P=0.04)$. Other staphylococcal species exhibited a decrease in resistance to chloramphenicol $(P<0.001)$ and an increase resistance to tobramycin $(P=0.01)$.

\section{Conclusions}

In conclusion, our data demonstrate that staphylococci are the most common microorganisms responsible for causing 
ocular infections. Antibiotic resistance profiles have not changed significantly between 2015 and 2020, indicating that antibiotic resistance remains a challenge. Therefore, continued surveillance of antibiotic resistance is recommended to guide therapy choices. Clinicians should consider these data when establishing empirical treatment strategies for ocular infections.

\section{Data Sharing Statement}

The data used to support the findings of this study are available from the corresponding author upon request.

\section{Acknowledgments}

This work was supported by the National Natural Science Foundation of China (81902103), the State Key Program of National Natural Science Foundation of China (81430007), the subject of major projects of National Natural Science Foundation of China (81790641).

\section{Disclosure}

The sponsor or funding organization had no role in the design or conduct of this research. No conflicting relationships exists for any author.

\section{References}

1. Fair RJ, Tor Y. Antibiotics and bacterial resistance in the 21st century. Perspect Medicin Chem. 2014;6:25-64. doi:10.4137/PMC. S14459

2. Laxminarayan R, Duse A, Wattal C, et al. Antibiotic resistance-the need for global solutions. Lancet Infect Dis. 2013;13(12):1057-1098.

3. Baquero F, Coque TM, Cantón R. Counteracting antibiotic resistance: breaking barriers among antibacterial strategies. Expert Opin Ther Targets. 2014;18(8):851-861. doi:10.1517/14728222.2014.925881

4. Hawser S. Surveillance programmes and antibiotic resistance: worldwide and regional monitoring of antibiotic resistance trends. Handb Exp Pharmacol. 2012;211:31-43.

5. Vasoo S, Barreto JN, Tosh PK. Emerging issues in gram-negative bacterial resistance: an update for the practicing clinician. Mayo Clin Proc. 2015;90(3):395-403. doi:10.1016/j.mayocp.2014.12.002

6. Asbell PA, Sahm DF, Shaw M, et al. Increasing prevalence of methicillin resistance in serious ocular infections caused by Staphylococcus aureus in the United States: 2000 to 2005. J Cataract Refract Surg. 2008;34 (5):814-818. doi:10.1016/j.jcrs.2008.01.016

7. McDonald M, Blondeau JM. Emerging antibiotic resistance in ocular infections and the role of fluoroquinolones. $J$ Cataract Refract Surg. 2010;36(9):1588-1598. doi:10.1016/j.jcrs.2010.06.028

8. Bertino JS. Impact of antibiotic resistance in the management of ocular infections: the role of current and future antibiotics. Clin Ophthalmol. 2009;3:507-521. doi:10.2147/OPTH.S5778

9. Holland EJ, McDonald MB, Parekh JG, et al. Antibiotic resistance in acute postoperative endophthalmitis. Ophthalmology. 2014;121(11): S1-S9; quiz S10-12. doi:10.1016/j.ophtha.2014.06.049

10. Ni N, Nam EM, Hammersmith KM, et al. Seasonal, geographic, and antimicrobial resistance patterns in microbial keratitis: 4-year experience in eastern Pennsylvania. Cornea. 2015;34(3):296-302. doi:10.1097/ICO.0000000000000352
11. Sharma S. Antibiotic resistance in ocular bacterial pathogens. Indian $J$ Med Microbiol. 2011;29(3):218-222. doi:10.4103/0255-0857. 83903

12. Gentile RC, Shukla S, Shah M, et al. Microbiological spectrum and antibiotic sensitivity in endophthalmitis: a 25-year review. Ophthalmology. 2014;121(8):1634-1642. doi:10.1016/j.ophtha.2014. 02.001

13. Chang VS, Dhaliwal DK, Raju L, et al. Antibiotic resistance in the treatment of Staphylococcus aureus keratitis: a 20-year review. Cornea. 2015;34(6):698-703. doi:10.1097/ICO.0000000000000431

14. Keay L, Stapleton F, Schein O. Epidemiology of contact lens-related inflammation and microbial keratitis: a 20 -year perspective. Eye Contact Lens. 2007;33(6):346. doi:10.1097/ICL.0b013e318157c49d

15. Toriyama K, Suzuki T, Shiraishi A. Characteristics of infectious keratitis in old and very old patients. $J$ Ocul Pharmacol Ther. 2018;34(8):565-569. doi:10.1089/jop.2018.0028

16. Kang BS, Kim MK, Wee WR, et al. Infectious keratitis in limbal stem cell deficiency: stevens-johnson syndrome versus chemical burn. Cornea. 2016;35(1):51-55. doi:10.1097/ICO.0000000000000677

17. Khor WB, Prajna VN, Garg P, et al. The Asia Cornea Society Infectious Keratitis Study: a prospective multicenter study of infectious keratitis in Asia. Am $J$ Ophthalmol. 2018;195:161-170. doi:10.1016/j.ajo.2018.07.040

18. Termote K, Joe AW, Butler AL, et al. Epidemiology of bacterial corneal ulcers at tertiary centres in Vancouver, B.C. Can J Ophthalmol. 2018;53(4):330-336. doi:10.1016/j.jcjo.2017.11.001

19. Asbell PA, Sanfilippo CM, Pillar CM, et al. Antibiotic resistance among ocular pathogens in the United States: five-year results from the Antibiotic Resistance Monitoring in Ocular Microorganisms (ARMOR) surveillance study. JAMA Ophthalmol. 2015;133 (12):1445-1454. doi:10.1001/jamaophthalmol.2015.3888

20. Chiquet C, Maurin M, Altayrac J, et al. Correlation between clinical data and antibiotic resistance in coagulase-negative Staphylococcus species isolated from 68 patients with acute post-cataract endophthalmitis. Clin Microbiol Infect. 2015;21(6):592.e591-598. doi:10.1016/j.cmi.2015.01.028

21. Chao J, Yumei Z, Zhiqun W, et al. Multidrug-resistant bacteria induce recurrent keratoconjunctivitis in a patient with common variable immunodeficiency: case report and literature review. Cornea. 2013;32(Suppl 1):S39-42. doi:10.1097/ICO.0b013e3182a2c7e6

22. Al-Omran AM, Abboud EB, Abu El-Asrar AM. Microbiologic spectrum and visual outcome of posttraumatic endophthalmitis. Retina. 2007;27(2):236-242. doi:10.1097/01.iae.0000225072.68265.ee

23. Clinical and Laboratory Standards Institute. Performance Standards for Antimicrobial Susceptibility Testing: Thirtieth Informational Supplement. Wayne, PA: Clinical \& Laboratory Standards Institute;2020. CLSI document M100-S30.

24. Ung L, Bispo PJM, Shanbhag SS, et al. The persistent dilemma of microbial keratitis: global burden, diagnosis, and antimicrobial resistance. Surv Ophthalmol. 2019;64(3):255-271. doi:10.1016/j. survophthal.2018.12.003

25. Austin A, Lietman T, Rose-Nussbaumer J. Update on the Management of Infectious Keratitis. Ophthalmology. 2017;124 (11):1678-1689. doi:10.1016/j.ophtha.2017.05.012

26. Geevarghese A, Shah P, Lopez J, et al. Common microbes and antibiotic resistance in ocular infections at an urban public tertiary care hospital. Ocul Immunol Inflamm. 2020;1-6. doi:10.1080/ 09273948.2020.1799033

27. Catalanotti P, Lanza M, Del Prete A, et al. Slime-producing Staphylococcus epidermidis and S. aureus in acute bacterial conjunctivitis in soft contact lens wearers. New Microbiol. 2005;28(4):345-354.

28. Deguchi H, Kitazawa K, Kayukawa K, et al. The trend of resistance to antibiotics for ocular infection of Staphylococcus aureus, coagulase-negative staphylococci, and Corynebacterium compared with 10-years previous: a retrospective observational study. PLoS One. 2018;13(9):e203705. doi:10.1371/journal.pone.0203705 
29. Silpa-Archa S, Dejkong A, Kumsiang K, et al. Poor prognostic factors in post-traumatic endophthalmitis following open globe injury. Int J Ophthalmol. 2020;13(12):1968-1975. doi:10.18240/ijo.2020.12.19

30. Jindal A, Pathengay A, Mithal K, et al. Endophthalmitis after open globe injuries: changes in microbiological spectrum and isolate susceptibility patterns over 14 years. J Ophthalmic Inflamm Infect. 2014;4(1):5. doi:10.1186/1869-5760-4-5

31. Hsiao CH, Chuang CC, Tan HY, et al. Methicillin-resistant Staphylococcus aureus ocular infection: a 10-year hospital-based study. Ophthalmology. 2012;119(3):522-527. doi:10.1016/j.ophtha.2011.08.038

32. Lin YH, Kang YC, Hou CH, et al. Antibiotic susceptibility profiles of ocular and nasal flora in patients undergoing cataract surgery in Taiwan: an observational and cross-sectional study. BMJ Open. 2017;7(8):e017352. doi:10.1136/bmjopen-2017-017352

33. Nithya V, Rathinam S, Siva Ganesa Karthikeyan R, et al. A ten year study of prevalence, antimicrobial susceptibility pattern, and genotypic characterization of Methicillin resistant Staphylococcus aureus causing ocular infections in a tertiary eye care hospital in South India. Infect Genet Evol. 2019;69:203-210. doi:10.1016/j.meegid.2019.01.031

34. Liu C, Ji J, Li S, et al. Microbiological isolates and antibiotic susceptibilities: a 10-year review of culture-proven endophthalmitis cases. Curr Eye Res. 2017;42(3):443-447. doi:10.1080/ 02713683.2016 .1188118
35. Watson S, Cabrera AM, Khoo P, et al. Keratitis antimicrobial resistance surveillance program, Sydney, Australia: 2016 annual report. Clin Exp Ophthalmol. 2019;47(1):20-25. doi:10.1111/ceo.13364

36. Lichtinger A, Yeung SN, Kim P, et al. Shifting trends in bacterial keratitis in Toronto: an 11-year review. Ophthalmology. 2012;119 (9):1785-1790. doi:10.1016/j.ophtha.2012.03.031

37. Peng MY, Cevallos V, McLeod SD, et al. Bacterial keratitis: isolated organisms and antibiotic resistance patterns in San Francisco. Cornea. 2018;37(1):84-87. doi:10.1097/ICO.0000000000001417

38. Tan SZ, Walkden A, Au L, et al. Twelve-year analysis of microbial keratitis trends at a UK tertiary hospital. Eye (Lond). 2017;31 (8):1229-1236. doi:10.1038/eye.2017.55

39. Jin H, Parker WT, Law NW, et al. Evolving risk factors and antibiotic sensitivity patterns for microbial keratitis at a large county hospital. Br J Ophthalmol. 2017;101(11):1483-1487. doi:10.1136/bjophthalmol-2016-310026
Infection and Drug Resistance

\section{Publish your work in this journal}

Infection and Drug Resistance is an international, peer-reviewed openaccess journal that focuses on the optimal treatment of infection (bacterial, fungal and viral) and the development and institution of preventive strategies to minimize the development and spread of resistance. The journal is specifically concerned with the epidemiology of
Dovepress

antibiotic resistance and the mechanisms of resistance development and diffusion in both hospitals and the community. The manuscript management system is completely online and includes a very quick and fair peerreview system, which is all easy to use. Visit http://www.dovepress.com/ testimonials.php to read real quotes from published authors. 